\title{
Managing complexity: Dealing with systemic crosstalk in bovine physiology
}

\author{
Barry J. Bradford, ${ }^{* 2}$ Kai Yuan, $\dagger$ and Caroline Ylioja* \\ *Department of Animal Sciences and Industry, Kansas State University, Manhattan 66506 \\ †Novi, Ml 48374
}

\section{ABSTRACT}

Dairy producers rely heavily on advisors with deep expertise in nutrition, reproduction, and health. However, a shift is occurring, driven both by farm size and by advances in biology. Larger dairy businesses can investigate management options with a degree of precision never before possible; simultaneously, the lines between the metabolic, immune, and reproductive systems are becoming blurred. For example, new research has revealed a surprising role for immune cells in regulating metabolism and documented the nutrient requirements of the immune system. The gut epithelium has garnered new attention as a tissue that actively manages the commensal microbiome, entrains the responses of the neonatal immune system, and provides a barrier limiting movement of molecules from the gut lumen. New hormone discoveries have added adipose tissue, bone, and muscle to the list of endocrine organs. Finally, nutrients are now seen not only as substrates and cofactors, but also as signals that can alter cellular function. What does all of this mean for the dairy industry? Consultants are increasingly reaching across disciplinary boundaries to best support the physiology of the cow. However, research is needed to translate proof-of-principle findings into applications in cattle. Key unanswered questions include the degree to which roles of the hindgut in monogastrics translate to ruminants, and whether some host-microbe crosstalk also occurs in the rumen; whether hormone release by storage organs during a catabolic state affects reproductive function; and the degree to which immunostimulation by dietary signals enhances or disrupts health and productivity. It is critical to address these questions with multiple approaches. Mechanistic studies provide a nuanced understanding of signal interactions, but large-scale commercial studies are needed to evaluate

Received August 17, 2015.

Accepted October 11, 2015.

${ }^{1}$ Presented as part of the ADSA Production Division Symposium: The Rumen and Beyond-Nutritional Physiology of the Modern Dairy Cow at the ADSA-ASAS Joint Annual Meeting, Orlando, Florida, July 2015.

${ }^{2}$ Corresponding author: bbradfor@ksu.edu effects on multiple production outcomes in the environment of interest, and meta-analyses best integrate findings into a cohesive understanding of responses to diet. Incorporating all aspects of animal health and productivity in management decisions will remain an art for the foreseeable future, but this should not dissuade the industry from pursuing a more holistic approach to management of the cow.

Key words: dairy cow, nutrition, nutrigenomics, nutraceutical, gastrointestinal microbiology

\section{INTRODUCTION}

The dairy industry has made impressive advances over the past century in productivity and resource efficiency. These improvements can be attributed to an increased understanding of the biology of the dairy cow, and the application of this knowledge to develop new technologies and improve management practices. Our understanding of nutrition has likewise developed, to the extent that the bulk of the opportunity for further advancement may now lie in exploring the crosstalk that exists between different tissue systems, their combined effects on nutrient metabolism, and how specific feed components affect tissue function.

Improvements in nutrition have allowed cows to express their increasingly high genetic potential for milk production, which has improved the efficiency of dairy production primarily by diluting maintenance costs (i.e., fewer cows and less feed needed to produce the same amount of milk). However, as demonstrated by VandeHaar et al. (2016), the steady increase in efficiency that we have witnessed through this mechanism in the past $70 \mathrm{yr}$ will not continue forever. Sooner or later, the dairy cow will approach her biological limit for capturing ingested energy as productive energy, largely due to trade-offs between level of DMI and residence time in the gastrointestinal tract. Therefore, to continue to improve resource efficiency in the dairy industry, we need to expand our focus to include other inefficiencies in the system.

The lost resources caused by morbidity, mortality, and infertility must contribute substantially to the suboptimal efficiency of the dairy industry, although a 
comprehensive analysis is lacking. To derive a minimal estimate of resource losses due to stressors, we considered losses from just heat stress (St-Pierre et al., 2003), mastitis (Bar et al., 2008), and hyperketonemia (McArt et al., 2015); we used financial losses as a proxy for wasted resources, but excluded veterinary costs. Based on the cited analyses, these 3 problems drain almost $\$ 2.2$ billion annually from the US dairy industry in the form of lost milk (direct and indirect effects) and death loss, representing over $5 \%$ of the $\sim \$ 40$ billion in dairy farm cash receipts for milk sold in the United States annually. If nutrition can be used to combat these problems, it is clear that there are major economic and resource efficiency benefits to be gained. Therefore, it is worthwhile to consider effects of nutrition on efficiency metrics beyond milk and DMI.

Our primary goal in this review is to highlight important scientific advances that might influence dairy nutrition, and to suggest ways that researchers and nutrition consultants can progress with these new insights in mind.

\section{THE CHANGING LANDSCAPE OF NUTRITION SCIENCE}

\section{An Evolving Field}

Perhaps the earliest American effort to comprehensively address the nutritional needs of cattle appeared in a book by Armsby (1880). At that time, substantial progress had already been made in understanding the digestion and assimilation of fat, carbohydrate, protein, and minerals. In the early 1900s, however, studies of single-grain diets for cattle and purified diets in monogastrics made it clear that these nutrients alone were insufficient to maintain optimal health and growth. This led to a period of rapid advances in understanding micronutrient requirements, particularly the identification of vitamins (Carpenter, 2003). By the end of this period, nearly all nutrients could be evaluated in terms of contributions to energetic needs, anabolic substrate requirements, or as cofactors in essential metabolic pathways. This relatively straightforward view of nutrition was dominant through most of the 20th century. In dairy nutrition, these concepts were generally applied to assess whether different diets would support a higher level of milk production, with incremental increases in productivity viewed as evidence that a nutrient was at least marginally inadequate in the control diet.

In many ways, this classical approach to nutrition ("Nutrition 1.0") might be considered overly simplistic today. We next highlight 5 key areas of nutrition science that have gradually supplanted this traditional view of nutrition with "Nutrition 2.0" (Figure 1).

\section{The Guts of the Matter}

Ruminant nutritionists, because they focus on foregut-fermenting animals with an obvious reliance on commensal microbes, have long recognized the need to "feed the rumen bugs" and maintain gastrointestinal health of cattle. Indeed, early publications studying the human gut microbiome leaned heavily on decades of previous work by rumen microbiologists (Bäckhed et al., 2005). Still, few would have predicted the vast impact of commensal microbes that has been revealed in the past 2 decades.

Given that cows depend heavily on the microbes inhabiting the rumen to convert indigestible plant mass to digestible compounds and essential nutrients, it is not difficult to imagine that the large, complex ruminal microbial population has enormous nutritional, physiological, and pathological interactions with the cow. More than 200 yr ago, the transfer of rumen contents was already being used as a therapeutic tool; the nutrients and microorganisms transferred into the rumen of a sick animal stimulate ruminal fermentation and motility, and there are likely undiscovered effects as well (DePeters and George, 2014). Some evidence suggests that individual animals can, by unknown mechanisms, cultivate a relatively consistent individualized microbiome, even in the face of a complete exchange of ruminal contents (Weimer et al., 2010). Another study (Jami and Mizrahi, 2012) examined rumen microbiota across individual animals and found that although the bacterial taxa may vary considerably between cows, they appear to be phylogenetically related, suggesting that ecological niches in the rumen select taxa that share similar genetic features. This individuality does not imply that diet changes cannot alter the rumen microbiome; many such examples have been reported (Firkins and $\mathrm{Yu}, 2015$ ). Rather, these findings suggest that animal-diet interactions drive the ecology of the rumen.

The more surprising findings have come from rodents, whose size and lack of dependence on fermentation allows investigators to more easily utilize gnotobiotic (germ-free) models and to establish near monocultures in the gut. Studies have now suggested that the composition of the intestinal microbiota directly or indirectly affects body composition, allergic inflammation, bone metabolism, cancer risk, atherosclerosis, and even brain function (Dorrestein et al., 2014; Sharon et al., 2014). Gut microbes can therefore play a huge role in mediating the effects of dietary nutrients on host physiology. For example, one high-profile publication showed that intestinal microbial metabolism of L-carnitine to trimethylamine- $N$-oxide accelerates atherosclerosis in mice (Koeth et al., 2013). This response was eliminated 


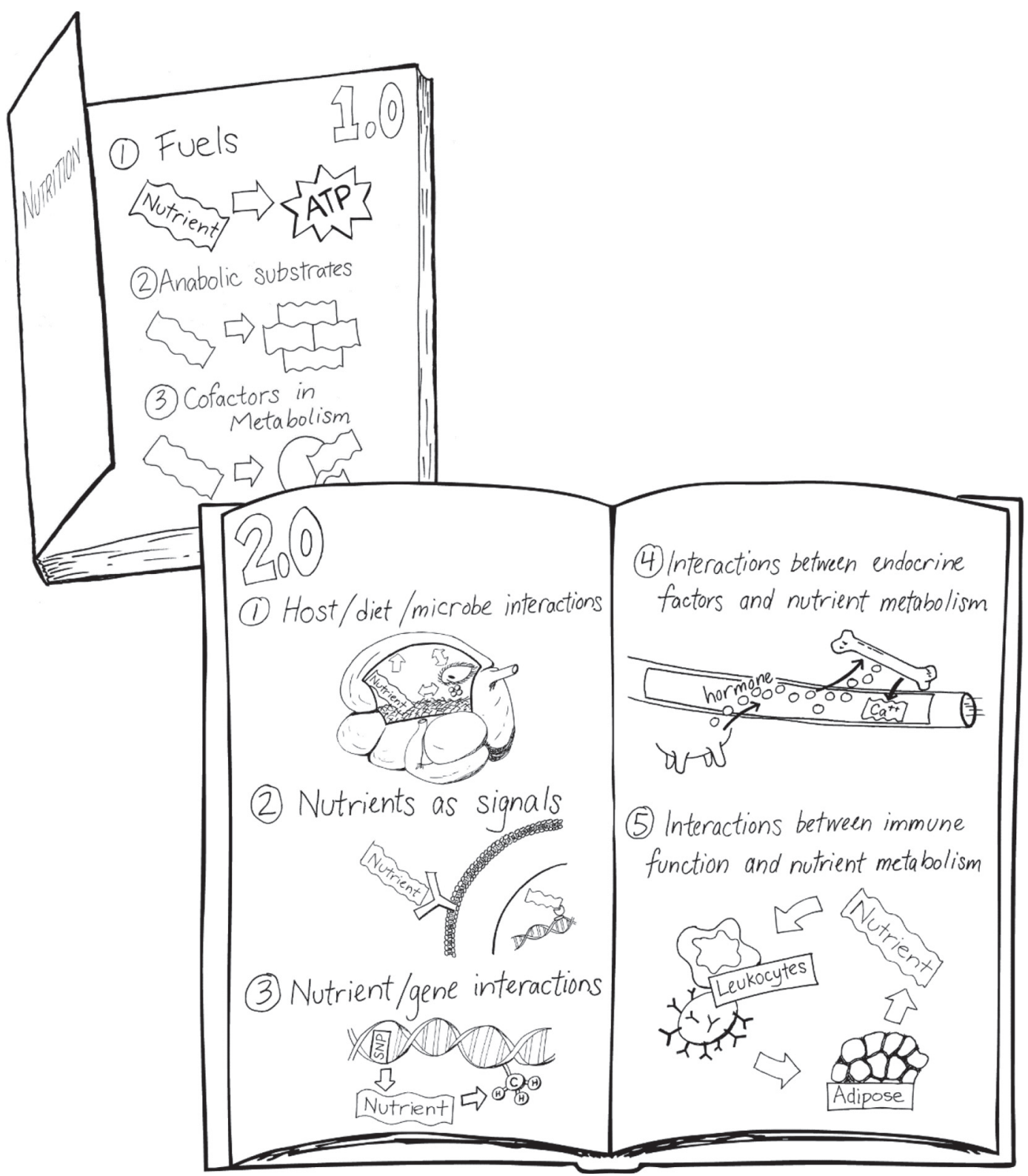

Figure 1. Early work in nutrition, continuing through the mid-20th century, revealed a variety of roles for nutrients that largely fit into 3 categories: fuels, anabolic substrates, and cofactors. This paradigm has been extremely useful for eradicating disease caused by gross nutritional deficiencies and for supplying the macronutrient needs of animals. However, discoveries in more recent decades have shown that Nutrition 1.0 was overly simplistic. These developments, collectively referred to as Nutrition 2.0, have revealed a variety of short- and long-term effects of nutrients, mediated by the gut microbiota, direct nutrient signaling, genotype-dependent interactions with the genome, interactions with an expanded list of metabolic hormones, and crosstalk with the immune system. These findings require a re-evaluation of how we think about diets.

if intestinal microbiota were concurrently suppressed. A similar example in ruminants is the case of toxicosis resulting from consumption of tropical legumes in the leucaena family (Hammond, 1995). Leucaena contains an unusual amino acid called mimosine that is converted to 3,4-dihydroxypyridine in the rumen; however, a ruminal bacterium called Synergistes jonesii is capable of degrading this toxic metabolite, preventing toxicosis. This species has been transferred out of its native range in ruminants of Hawaii to prevent leucaena toxicosis in Australian ruminants.

To maintain the symbiotic relationship, the host immune system must exert complex regulation of mucosal immunity to remain hypo-responsive to commensal bacteria while combating invasive pathogens effectively (Macpherson and Harris, 2004). A recent paper even documented that the mouse intestinal epithelium actively synthesizes and releases "food" for its commensal 
neighbors when illness introduces pathogenic competitors and disrupts normal nutrient supply (Pickard et al., 2014). It is now clear that in the intestine, crosstalk between microbes, epithelial cells, and immune cells is dynamic and critical to the health of the host animal.

The regulation of gastrointestinal tract function, the commensal microbial community, and their interactions have become an important topic of ruminant nutrition research and will provide us with further insights into dietary effects on productivity and health. One very clear outcome of this is that diets can dramatically alter gut morphology and physiology, often through effects on the microbiota. For example, adaptation of the rumen epithelium may be important in alleviating the detrimental effects of ruminal acidosis. Rumen papillae not only increase in size when animals are transitioned to a high grain diet to increase the surface area for absorption (Odongo et al., 2006) but also undergo structural and functional adaptations (Steele et al., 2011). Although it has been less studied, the hind gut may also respond to shifts in nutrient availability during ruminal acidosis (Steele et al., 2016).

Other stressors, particularly heat stress, can also disrupt barrier function of the gut, and the subsequent invasion of intestinal microbes or their cellular constituents may underlie many of the problems associated with such stressors (Zhang et al., 2013; Baumgard et al., 2015). This is directly relevant to nutritionists, as there is some evidence that nutrients can partially alleviate this effect (Chauhan et al., 2014).

Although recent work has generated groundbreaking insights into the role of microbes in several physiological processes, we still know very little about the functional implications of these findings in bovine physiology. There are many important but unanswered questions in this area. To what degree do studies of the hindgut microbiota in monogastrics translate to ruminants (Liang et al., 2015)? Does host-microbe crosstalk occur in the rumen (Trevisi et al., 2014)? How does the host discriminate between symbiotic and pathogenic microbes to trigger appropriate immune responses? Are there unrecognized microbial products that have a meaningful effect on bovine biology? How do gut communities assemble after birth, and do different calf rearing strategies affect the mature ruminal or intestinal microbiome (Jami et al., 2013)? Are there dietary strategies that consistently improve gut barrier function during stress?

It may be many years before we have a relatively clear understanding of the complex interactions of diet, host, and microbes in the ruminant. Nevertheless, the possibilities to affect the energetics, immunity, and health of ruminants through alterations in gut microbiology and morphology are broad. This is one key reason why non- nutritive feed additives have been so popular in dairy nutrition (Wallace and Newbold, 1992; Duffield et al., 2008; Yuan et al., 2015), and mechanisms underlying their effects are worthy of continued study.

\section{Nutrients as Signals}

Many decades ago, the author Lin Yutang (1937) observed, "The Chinese do not draw any distinction between food and medicine." Perhaps science has now caught up with traditional Chinese wisdom. In contrast to the view that nutrients alter function by their availability (or lack thereof) for chemical reactions, we now understand that physiological sensors respond to a wide array of nutrients from every nutrient class (Efeyan et al., 2015). By acting as ligands for intracellular and extracellular receptors, as well as via allosteric interactions with enzymes, nutrients have taken on roles that were previously ascribed only to drugs and hormones.

This development has not gone unnoticed in the ruminant nutrition world. For example, studies have characterized bovine $\mathrm{G}$ protein-coupled receptors for VFA (Wang et al., 2009) and long-chain fatty acids (Manosalva et al., 2015), explored the supranutritional effects of niacin (Morey et al., 2011; Kenéz et al., 2014), and detailed vitamin $\mathrm{D}$ receptor influences on immunity (Nelson et al., 2012). Viewing nutrients as signals as well as substrates can change how requirements need to be modeled in formulation or metabolism software. For example, some evidence suggests that the singlelimiting AA paradigm is inconsistent with cellular signals that drive milk protein synthesis. Increased delivery of nonlimiting EAA and even fuels has supported increased protein synthesis, potentially due to integrated regulation by endocrine and nutrient sensing pathways (Rius et al., 2010; Arriola Apelo et al., 2014), although this does not always correspond with milk protein yield (Doelman et al., 2015).

\section{Nutrient-Gene Interactions}

Terms such as "nutrigenomics" are used in a wide variety of ways, such that almost any effect of nutrition on DNA is implicated. Certainly the roles of nutrients as cofactors, substrates, and signals in DNA replication, repair, transcription to mRNA, and even alternative splicing of mRNA are worthy of study, and these mechanisms are integral to many of the dietary responses discussed throughout this review. Here, though, we highlight what we consider to be the 2 most exciting topics in this area: epigenetic effects of nutrients and genotype-dependent responses to nutrients.

Epigenetics. Beyond short-term effects of nutrients, the potential for early-life nutrition to have long-term 
impacts on animals has been recognized for many years. However, the development of the field of epigenetics has expanded the reach of this concept and dramatically raised its profile. Epigenetics seeks to understand the inheritance of traits mediated by mechanisms other than DNA sequence (Feeney et al., 2014), largely through changes to the DNA structure.

This field of study focuses primarily on transgenerational effects, and some very detailed studies have now demonstrated large epigenetic-mediated effects due to differences in nutrient supply. Folic acid deficiency in dams has long been known to lead to birth defects, but recent studies have demonstrated that folic acid deficiency in sires can cause similar developmental problems (Lambrot et al., 2013). Paternal deficiency of folic acid (essential for methyl group transfer) resulted in many changes in sperm DNA methylation and subsequently in placental gene expression, and greatly increased early embryonic loss as well as developmental abnormalities in offspring. This is an example of a transgenerational effect of a classical nutrient deficiency, but there is evidence that nutrient signals can affect these processes as well. In particular, butyrate's role as a histone deacetylase inhibitor may be important in ruminant epigenetics (Wu et al., 2012).

The modifications of DNA structure that mediate these transgenerational effects also have important roles in regulatory physiology within an animal's life. For example, DNA methylation patterns are dramatically altered during mammary gland development (Dos Santos et al., 2015), and epigenetic changes are heavily involved in responses to mastitis (Vanselow et al., 2006; Chang et al., 2015).

To date, only a few studies have evaluated dietary effects on DNA modification in ruminants. Large changes in forage:concentrate ratio influenced both histone $\mathrm{H} 3$ acetylation and methylation of select genes in mammary tissue of lactating dairy cows (Dong et al., 2014). Another study evaluated the effect of methionine supplementation of dairy cows on the transcriptome of preimplantation embryos (Peñagaricano et al., 2013). Remarkably, a subtle difference in methionine supplementation (1.89 Met vs. 2.43 Met, \% of MP, from parturition until embryo flushing) in the maternal diet was sufficient to cause differential expression of 276 genes in embryos, including those related to embryonic development and immune response. Given that Met is a critical methyl group donor, these results may have been mediated by effects on DNA methylation. Others have reported that DNA methylation in oocytes differed in cows during early versus mid lactation, potentially associated with negative energy balance (O'Doherty et al., 2014). Using a quantitative approach, GonzálezRecio et al. (2012) explored phenotypic evidence for an epigenetic impact of concurrent lactation during gestation on offspring milk production, and suggested that the findings should influence diet formulation for pregnant lactating cows. Nutritional epigenetics certainly raises mind-boggling questions about how long a farm may suffer from the consequences of a poor nutrition program.

Individualized Nutrition. One of the selling points for the initial human genome project was that it would open the doors to personalized medicine, including personalized nutrition. Although these potential benefits were clearly over-sold at the time, we are finally beginning to see the first glimpses of what this could look like in the future (Gibney and Walsh, 2013).

The core concept behind individualized nutrition is that genetic differences between individuals should influence their nutrient requirements or ability to respond to specific nutrients. Some clear, mechanistically sound interactions have been documented for humans. For example, riboflavin supplementation lowers blood pressure only in patients with a certain mutation in the methylenetetrahydrofolate reductase gene (Gibney and Walsh, 2013).

Many studies over decades have evaluated interactions of nutrition and breed on productivity in ruminants, and some have considered responses to diets across a range of genetic merit for milk production (Friggens et al., 2013). However, very few studies have attempted to evaluate interactions of diet with specific genetic polymorphisms. One exciting example of the potential of such approaches was the work of Kononoff et al. (2013). This study showed that feedlot cattle with a specific leptin genotype had an $8 \%$ decline in DMI and a $9 \%$ decrease in marbling score when fed the $\beta$-agonist zilpaterol hydrochloride, whereas cattle with the alternative genotype showed no response to zilpaterol for these outcomes. Given that the same SNP is associated with milk and protein yield (Buchanan et al., 2003), the potential for leptin genotype-dependent responses to diet in dairy cows seems worthy of investigation. Several other polymorphisms that have a meaningful effect on milk yield and composition have been described, and more are certain to come in this era of cheap and rapid genome sequencing. Individualized feeding programs based on sensitive genetic polymorphisms could allow for efficiency gains that are not accessible when all genotypes are fed in common.

\section{Rewriting the Book on Endocrinology}

In a general biology textbook published 20 yr ago, a total of 9 "major" endocrine organs were described (Campbell, 1996). Today, it might be more efficient to list major organs in the body without an identified 
endocrine role. Notably for nutritionists, many of the newly recognized endocrine factors are directly involved in regulation of nutrient metabolism and partitioning.

The gastrointestinal tract was added to the list of accessory endocrine organs quite early: cholecystokinin was first described in detail in the 1960s. However, gut peptides have expanded both in numbers and in their known actions in the past $20 \mathrm{yr}$. In general, sensory cells in the small intestine respond to the presence of nutrients there by releasing these hormones, which then signal other organs to respond to meals. These intestinal peptides have many effects on the body but most are logical responses to a nutrient load in the gut; they stimulate bile and insulin secretion, slow motility of the upper gut, and promote safety. In transition cows, gut peptide concentrations increase more than 2-fold in early lactation as cows increase feed intake and energy balance (Relling and Reynolds, 2007). Ghrelin is an atypical gut peptide, as its secretion is stimulated by the absence of nutrients, signaling hunger. Ghrelin concentrations spike dramatically just before normal feeding times in animals fed on a regular schedule (Sugino et al., 2002), possibly helping to explain why animals tend to consume meals at these times even with feed available immediately before feeding. Most gut peptide work in dairy cattle has focused on whether these hormones can explain the decrease in feed intake in cows fed supplemental fat. Multiple studies have shown that fat, especially unsaturated fat, promotes increased concentrations of cholecystokinin and glucagon-like peptide-1 and appears to prevent premeal increases in ghrelin (Bradford et al., 2008), which would all be expected to suppress feed intake.

The liver, like the gut, has long been known to be an endocrine organ because it secretes IGF-1. Beyond this hormone, the liver has largely been ignored in endocrinology, but the discovery of several interesting hepatokines in recent years is changing this. One example, fibroblast growth factor 21 (FGF21), is a novel hormonal factor in the regulation of metabolic adaptations during energy deficiency, including stimulation of ketogenesis. Circulating FGF21 is greatly elevated in the transition dairy cow (Schoenberg et al., 2011), and expression of FGF21 during this time can be further enhanced by overfeeding during late gestation (Khan et al., 2014). Liver-derived FGF21 may be a signal coordinating the liver and other organs in early-lactating dairy cows, and dietary strategies that modulate FGF21 production could potentially be used to alter ketogenesis.

Kennedy (1953) first suggested that a "lipostat" in the body must relay information about adipose stores to the brain to allow for adaptation (e.g., in feed intake, activity) to meet a set point for fat stores. This prescient idea stood for over 40 years before the discovery of leptin in 1994 provided an endocrine factor matching Kennedy's description. This opened the door to a flurry of activity on the endocrine roles of adipose tissue, and dozens of adipose-derived paracrine and endocrine factors have now been described (Sauerwein et al., 2014). Among them, resistin - a hormone that decreases insulin sensitivity - is particularly interesting in transition cows. Resistin expression in adipose tissue increased by 14 -fold in lactating compared with nonlactating cows, whereas resistin expression in mammary tissue decreased by $65 \%$ during lactation (Komatsu et al., 2003). Conversely, adiponectin, the antiinflammatory adipokine that increases insulin sensitivity, is suppressed in early lactation (Giesy et al., 2012; Singh et al., 2014). Both hormonal shifts are consistent with the induction of systemic insulin resistance in early lactation to drive nutrients to the mammary gland.

Still more tissues have been identified as sources of metabolic hormones. There is strong multi-species evidence that the mammary gland can "demand" calcium release from bone through secretion of parathyroid hormone-related protein, stimulated by serotonin signaling (Marshall et al., 2014). Not to be outdone, bone has also claimed an endocrine role. Bone-forming osteoblast cells produce a protein hormone called osteocalcin; serum osteocalcin is highest early in life, declines with age, and declines further in the days immediately following calving, corresponding to relative rates of bone formation (Sato et al., 2011). This hormone has some surprising effects on adipose tissue and pancreatic function (Oldknow et al., 2015). Finally, skeletal muscle is able to deploy its own endocrine factors, including myonectin, a hormone that stimulates utilization of nonesterified fatty acids in a variety of tissues (Gamas et al., 2015).

By and large, these recently described endocrine factors have only nuanced effects on systemic physiology in animals in the absence of metabolic challenges. However, it is entirely possible that they play important roles during the dramatic activation of catabolic processes in the transition to lactation, and the large changes in blood concentrations of liver, adipose, and bone-derived hormones in the transition period are consistent with this possibility. The increased complexity of endocrinology today opens up many more possibilities for nutrients - both stored and dietary - to affect a broad range of physiological processes through alterations in hormone release.

\section{Immunological Interactions with Metabolic Machinery}

There has been a growing interest in recent years both in effects of nutrient supply on immune function 
and in the regulatory roles of immune cells on nutrient metabolism and partitioning. Some eye-opening findings have changed our view of the immune system's effect in healthy animals.

The quantitative energetic cost of immune activation is a long-standing question in animal biology. Indeed, it has remained a standing question because the disruptions to normal function that occur during illness make it difficult to isolate the energetic cost of immune system activation from other effects on energetics. However, a handful of studies that have measured the effects of systemic inflammation on resting metabolic rate suggest a mean $\sim 25 \%$ increase in maintenance requirements during immune activation (Lochmiller and Deerenberg, 2000). In lactating cows consuming $4 \times$ maintenance intake, this would equate to an $8 \%$ decrease in net energy available for lactation, suggesting that the suppression of DMI during inflammation (potentially $34 \%$ or more; Kushibiki et al., 2003) may have a greater effect than the increase in energy demands. Alternatively, the preferential use of glucose as a fuel by immune cells may cause more problems than the energy drain per se (Ingvartsen and Moyes, 2013).

Findings in the past 2 decades have demonstrated that many nutrients and metabolites can directly alter the function of leukocytes attempting to respond to signals of infection (Ingvartsen and Moyes, 2013; Sordillo and Mavangira, 2014). Many of these effects are based on the nutrients-as-signals paradigm. For example, metabolites associated with ketosis directly impair leukocyte function (Grinberg et al., 2008; Youm et al., 2015), potentially providing a mechanistic link underlying epidemiological associations between ketosis and infection.

Discoveries regarding the regulatory roles of immune cells in normal metabolic function have been even more fascinating. Many effects of resident macrophages on metabolic organ function have been reported in obesity models (Odegaard and Chawla, 2013). However, even if this extreme physiological state is excluded, there is strong evidence that adipose tissue macrophages regulate both lipolysis during fasting (Kosteli et al., 2010) and thermogenesis in brown adipose tissue during cold exposure (Nguyen et al., 2011), that immune cells (likely liver $\mathrm{T}$ cells) suppress gluconeogenesis through secretion of IL-13 (Stanya et al., 2013), and that regulatory T-cell populations in the gut and adipose tissue are critical for normal function of these tissues (Lu et al., 2015).

Ultimately, the tight bidirectional links between metabolism and immunity support the hypothesis that these system are inextricably linked through coevolution; in fact, many of the functions of the immune and metabolic systems are found in a single integrated organ in some lower animals (Hotamisligil, 2006). Considered in this light, the idea that diet can directly affect immune function-and that immune function affects nutrient metabolism - seems far less surprising.

\section{Implications of Nutrition 2.0 for Feeding Dairy Cattle}

Discussions in animal nutrition are not often framed in this manner, but the 5 developments we highlight have been affecting our field for some time already. In fact, dairy nutrition has a fascinating story to tell about the effects of dietary lipid, starch, and fiber on ruminal microbe populations, which can lead to the production of bioactive lipids that suppress milk fat synthesis (Harvatine et al., 2009). Diet-induced milk fat depression incorporates effects on the microbiome, nutrients acting as signals, and potentially even genotype-dependent nutrient responses (Rincon et al., 2012), making it among the best examples of this revised approach to nutrition science.

Dairy nutritionists, then, have already adopted "Nutrition 2.0" to some extent. In addition to the examples integrated into the previous discussion, innovative scientists are now asking whether entrainment of internal circadian rhythms by feeding schedule affects dairy cattle productivity (Plaut and Casey, 2012; Rottman et al., 2014), whether transfer of endocrine factors in colostrum can affect calf physiology (Hammon et al., 2013), and how diet affects developmental physiology through effects on microRNA that disrupt protein translation (Meale et al., 2014). The question is how prevalent these complexities are, and whether our approaches to some nutritional problems are missing the mark because of our poor understanding of the underlying mechanisms.

\section{INCORPORATING TRAUMATIC TIMES INTO NUTRITION PROGRAMS}

It is easy enough to get wrapped up in new findings and lose sight of the big picture for commercial dairy producers. The reality is that most new findings are unlikely to dramatically alter the core diets that we feed to dairy cattle, because if these mechanisms have a large effect, then it is likely that nutrient profiles required to support them have already been reached through trial and error. The most likely overlooked opportunities to improve health and productivity therefore occur during the short windows of time when normal homeostasis is disrupted by disease, environmental challenges, or physiological transitions. It is our argument that the field of dairy nutrition can move forward in part by more systematically considering these "traumatic 
times" in determining what ideal nutrition programs look like.

It is worth noting that this idea is not really new and certainly not ours. Indeed, a simple review of the dairy nutrition literature over the past 50 yr nicely demonstrates that this is a long-term change in outlook in the discipline (Figure 2). In the mid-20th century, dairy nutrition research remained focused on establishing nutrient requirements to support ever-increasing genetic potential for milk production (Nutrition 1.0). However, a gradual shift became apparent beginning in the 1970 s, and today nearly $40 \%$ of papers in our field focus on nutrition during periods of stress (Nutrition $2.0)$.

\section{How to Define Nutrient Requirements?}

Animal nutritionists have traditionally defined requirements in a relatively simplistic way: by assuming there is a certain supply of a nutrient above which no additional increase in productivity can be observed. Even for animals in a relatively stable situation, this simple concept can become problematic to apply to experimental data (St-Pierre and Weiss, 2012). Defining requirements where they matter - on farms that deal with disease outbreaks, heat waves, and animal- to-animal variability - is even more challenging. Past National Research Council (NRC) committees have recognized this challenge and put forth recommendations that accounted for such factors where possible, primarily for a few micronutrients where a critical mass of studies with disease outcomes had been conducted (NRC, 2001). However, one difficulty in this respect is the lack of data upon which to base recommendations. This is compounded by the long-term effects that must be considered now, because nutrient deficiencies may not affect animals (particularly calves) in a quantifiable manner until long after the period of deficiency is over.

Nutrient Requirements Are Altered by Stress Scenarios. Our traditional definition of nutrient requirements has certainly allowed for different physiological states or demands to alter nutrient requirements (lactation being an extreme example). Likewise, many experiments have shown that responses to nutrients can differ depending on the stressors placed on an animal, which can be interpreted as evidence that nutrient requirements are altered in these traumatic times.

The nutrients and stressors that fit in this category are many and varied, but a few examples can make the point. Heat stress is one condition that clearly affects feed intake and nutrient demands of lactating cattle. Cows in heat stress conditions show signs of decreased

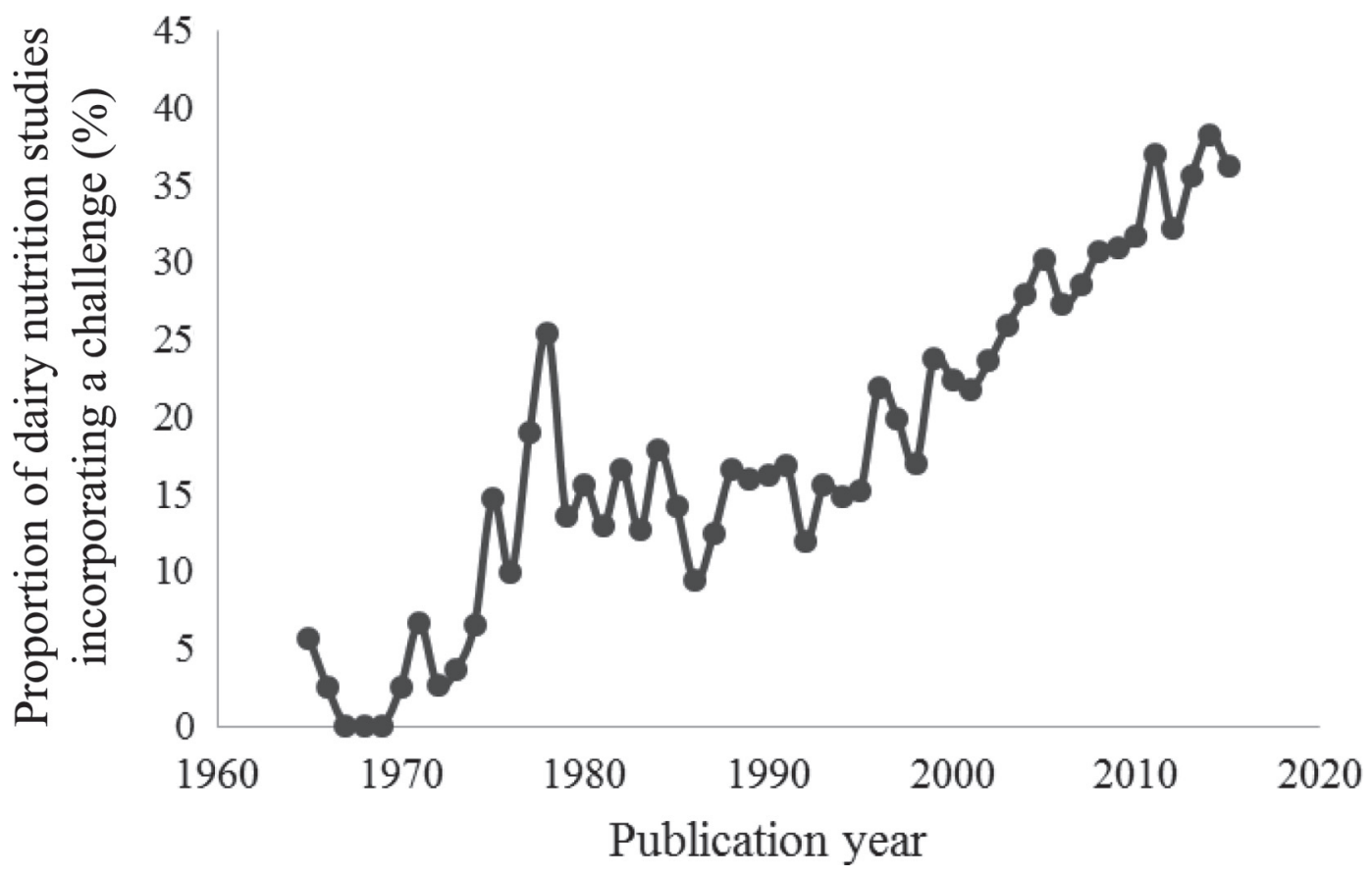

Figure 2. Dairy nutrition studies have increasingly focused on periods of physiological stress over the past 50 yr. The PubMed database (www.ncbi.nlm.nih.gov/pubmed) was searched for dairy nutrition publications using these terms: (dairy or Holstein) and (cow or cattle) and (dietary or diet or TMR or ration or feed or feeding). The subset of those studies that included a stressor was identified by searching for the above terms and (health or challenge or stress or disease or transition). This strategy returned a total of 9,624 publications, of which 2,316 included at least one of the stress terms (search date: July 13, 2015). 
bone formation as DMI decreases (Kamiya et al., 2010), and a meta-analysis suggested that cows respond more favorably to increasing dietary $\mathrm{Ca}$ in warmer months (Sanchez et al., 1994). Infectious challenge models can provide an excellent means to evaluate nutrient requirement during illness, although such studies are often conducted with sample sizes too small to reasonably detect differential responses by diet. However, one interesting study did demonstrate that ascorbic acid, a nonessential nutrient for ruminants, improved recovery of milk yield and ruminal activity following an intramammary endotoxin challenge (Chaiyotwittayakun et al., 2002). The transition to lactation is another period of stress, particularly for cows that have excess body condition. Zahra and colleagues (2006) reported that dietary choline improved the performance of cows in early lactation, exclusively through effects on cows with BCS $\geq 4$ at parturition, suggesting an increased choline requirement in this physiological state.

Can Feed Components Promote Robust Responses to Adversity? There are also examples of diet components affecting animal performance during stress periods where the response cannot easily be classified as meeting a heightened nutrient requirement. Fluctuation in diet fermentability, whether through shifts in digestibility of feed components or changes in diet composition, can cause subacute ruminal acidosis and milk fat depression. A study designed specifically to evaluate the resilience of cows in the face of such a diet challenge found that feeding a Saccharomyces cerevisiae fermentation product prevented milk fat depression during the challenge, despite the additive having no effect on milk parameters during the baseline period (Longuski et al., 2009). A similar additive prevented the decline in overall health scores of calves challenged with a live vaccine even though it had few effects before the challenge (Kim et al., 2011).

Many other studies have investigated the effects of dietary components during stress periods, but in many cases there was no evaluation of responses during a more stable stage of the production cycle. Nevertheless, the examples noted here clearly demonstrate that diet can confer improved resilience to a variety of stressors.

Ingredient Interactions. One of the challenges in dealing with feed components that may confer increased ability to handle stressors is that, in many cases, the precise mode of action is unclear. This presents a problem when formulating complete diets, because there may be two or more ingredients with well-supported claims for addressing a problem in a herd, but it is not obvious exactly how the ingredients will affect health and performance when fed together. For example, choline metabolism intersects with methionine and other methyl donors, and there is some evidence of antago- nistic interactions between dietary choline and RUP (Hartwell et al., 2000). Questions about antioxidant nutrient requirements and potential for substitutions are particularly common (Smith et al., 1984), with dual roles of some antioxidant compounds generating additional complications (Michal et al., 1994).

Given the novel complications that Nutrition 2.0 has introduced, many levels of potential nutrient interactions exist; one nutrient can affect the response to another by modifying microbial metabolism, endocrine status of the animal, abundance of metabolic enzymes, and so on. These complex nutrient effects and potential interactions make it critical that nutrients are evaluated in vivo in diets that mimic field applications as much as possible.

\section{Decision-Tree Nutrition Programs}

If the key to continued improvements in nutrient efficiency lies in providing better nutritional support during traumatic times, then we must consider how best to accomplish that goal. Clearly, this view will require more management input and flexibility than the current situation, where a sizable minority of farms feed all lactating cows a single diet (Contreras-Govea et al., 2015), and many others feed early-lactation cows separately but otherwise feed a uniform lactation diet. The first major step toward this way of thinking has been accomplished already with the widespread adoption of targeted, carefully considered diets for dry cows in late gestation. This change, particularly the adoption of anionic diet strategies for prevention of milk fever, ranks as one of the great success stories in our field (Goff, 2006). Where else can this type of approach help?

Clearly, targeted feeding in early lactation has already been identified by many producers and consultants as a worthwhile investment. These cows are often already separated for close observation, limiting the management cost of grouping for targeted feeding. Many feed additives or supplements that are cost-prohibitive across the lactation can be fed effectively for 2 to 4 wk, particularly when potential carryover effects are considered (Piantoni et al., 2015). Other opportunities also exist; for example, many larger dairies operate hospital pens for cows being treated for mastitis or other problems, but it is rare to hear of dairies that offer any unique nutritional support to these cows. Heat stress is addressed on some farms through seasonal changes in diets to try to accommodate the expected decrease in feed intake. However, targeted supplementation of protective nutrients immediately before expected heat waves may have much greater potential (Dunshea et al., 2013), in part because the short-term nature of this strategy opens up a range of possibilities that would 
be cost-prohibitive or even toxic over longer periods (Chauhan et al., 2014).

In addition to considering more flexible and variable feeding of groups, new monitoring and feeding technologies allow for even large farms to consider more individualized nutrition for cows. Environmental, disease, biometric feedback, and even genetic variables can be utilized as inputs into nutrition programs that are capable of cow-specific supplementation or multiple feeding groups to which cows can be allocated (Meijer and Peeters, 2010). We conceptualize this as "decision tree" nutrition as opposed to simply utilizing average animal characteristics and production levels to drive ration formulation.

To take full advantage of the potential effect of nutrition on dairy farm productivity, nutritionists need to seek the input of other experts. Indeed, a consistent theme running throughout Nutrition 2.0 is the effect of nutrition on longer-term outcomes such as fertility and health (LeBlanc et al., 2006), and dairy producers will benefit most when nutritionists work together with veterinarians and other key players to identify problems and seek cost-effective solutions.

\section{RESEARCH NEEDS AND THE MODERN DAIRY}

Working as a dairy scientist today can be an intimidating task; our clientele (both consultants and producers) are more educated and less dependent on universities for information than at any point in the past. As the core questions in Nutrition 1.0 have been answered, there has been a clear downsizing of dairy nutrition faculty and university dairies across the United States. However, it is our opinion that public sector research is just as essential today as ever before, in part because there are so many novel opportunities to seek out answers raised by Nutrition 2.0. We believe that important nutrition discoveries necessary to continue to improve the resource efficiency of the dairy industry can be achieved through a combination of 3 distinct approaches to research: proof-of-concept work, large field studies, and meta-analysis.

\section{Proof-of-Concept Research}

The complexities inherent in Nutrition 2.0 are daunting but also exciting. Nutrients are much more powerful tools than we once thought, and there are many interesting ideas to test. Today, dairy scientists have tremendous abilities to ask narrow questions in very controlled ways; we have access to a variety of bovine cell culture models, the bovine genome has enabled much more in-depth analysis of both transcript and regulatory protein responses to diets, and dairy cattle are abnormally cooperative subjects for longitudinal studies. Therefore, both in vitro models and small, intensive in vivo studies remain extremely useful tools for investigating novel ideas, identifying modes of action, dose titrating, and screening for nutrient interactions. In particular, challenge studies, where specific stressors are intentionally introduced, provide a unique and unbiased means by which to assess whether diet components offer any protection against that stressor. Many excellent examples of proof-of-concept studies have already been highlighted throughout this paper.

\section{Large Field Studies}

As of 2012, there were approximately 1,800 dairy farms in the United States with at least 1,000 cows in milk (USDA, 2014). These large farms, their merits or shortcomings aside, provide opportunities to conduct research with far greater statistical power than can be achieved on most university dairies. In fact, many of the most important questions raised in Nutrition 2.0 involve dichotomous outcomes (pregnant or not, culled or not) that inherently require larger sample sizes to provide any hope of detecting meaningful differences.

Studies on commercial farms can often provide the strongest evidence upon which to base recommendations for producers. These studies are typically done in environments that are quite similar to at least a portion of the industry, and the large sample sizes allow for the assessment of multiple economically important outcomes. The study of Lima et al. (2012) provides a nice example of why this matters. These investigators worked with commercial farms to evaluate responses to feeding supplemental choline prepartum through peak lactation or just prepartum. First, this approach allowed them to document substantially better outcomes when the supplement was also fed postpartum rather than only prepartum. Second, because they were not limited by a small sample size, they were able to observe a surprising reduction in the incidence of mastitis, a disease not directly associated with choline's purported mode of action.

A major limitation to the use of commercial farms for dairy nutrition research is the need to have sufficient replicates of the experimental unit. In studies where treatments are applied to a pen, this serves as the experimental unit, and having sufficient observations to detect a difference in fertility or disease incidence requires substantial numbers of cows, particularly with the pen sizes used on most large dairies. This challenge is not insurmountable when cows can be managed in relatively stable groups during lactation (Reis et al., 2012). However, this is exceptionally difficult for peri- 
partum treatments, when cows would have to be randomly assigned across at least 4 pens prepartum (for 2 treatments with replicated pens) and then directed to the correct corresponding postpartum treatment pen. These problems have been overcome in the past by using injectable nutrient supplementation strategies (Machado et al., 2013) or by labor-intensive individual supplementation in freestall lock-ups (Lima et al., 2012; Zaworski et al., 2014). However, the growing prevalence of robotic milking systems, and the opportunity to use more traditional in-parlor feeding systems, is beginning to offer a technical solution to allow nutritional treatments to be applied to individual cows in a laborefficient manner on commercial dairies (Bach, 2014).

\section{Meta-Analysis}

Most proof-of-concept studies and almost all field studies in dairy nutrition fail to adequately address potential interactions of specific diet components, because it is impractical to test all such interactions. Many studies are also underpowered for at least some relevant outcomes (i.e., health and reproduction). Therefore, there is much to be learned by attempting to integrate the results of multiple studies in an unbiased, quantitative manner. Fortunately, statistical approaches enabling this type of meta-analysis are now firmly established and are increasingly used by dairy scientists to address lingering questions about the biological effect of nutrients and their potential interactions.

Meta-analyses, when conducted properly, provide 3 very important insights. First, they can assess the likelihood of publication bias in the literature around a specific topic. Publication bias arises when either positive or negative responses to a treatment are preferentially published. This can occur for any number of reasons, including pressure from sponsors, limited enthusiasm on the part of investigators, and hesitance of reviewers and editors to publish "boring" negative results. Second, meta-analyses can provide an overall effect size estimation with substantially more precision than individual studies can offer. Finally, evaluation of heterogeneity across studies allows for meta-analysis to seek evidence of differential response sizes and to associate differential responses with potential explanatory factors. The investigation of heterogeneity requires the most power but is also potentially the most valuable outcome of meta-analysis in Nutrition 2.0.

Meta-analyses published in the past $10 \mathrm{yr}$ have made some important contributions to our understanding of health (Bourne et al., 2007) and reproductive (Rodney et al., 2015) responses to nutrients, along with many insightful meta-analyses on production responses to a variety of dietary components. The importance of meta-analysis for providing advice to producers moving forward should be considered by all dairy scientists, for several reasons. First, the quality of reporting on study methods directly affects the utility of published data for inclusion in meta-analysis, particularly when explanatory factors underlying heterogeneous responses are sought (Lean et al., 2016). Second, the potential for publication bias to lead to misinformation and misguided on-farm decisions should provide additional motivation for investigators to overcome internal and external barriers to publishing negative results. Finally, investigators will likely be pushed to share more data at the level of individual observations in the future. Although this can understandably make scientists uneasy, the power of large databases of individual observations for meta-analysis and modeling would certainly move the field forward at a faster rate. The National Animal Nutrition Program is likely to play an important role in such efforts in the United States (https://nanp-nrsp-9. $\operatorname{org} /$ ).

\section{CONCLUSIONS}

Feed efficiency has traditionally been thought of in simple terms of milk output per feed input, but nutrition science continues to reveal novel mechanisms by which diet can affect many other economically important outcomes, including health, fertility, and offspring performance. As the dilution of maintenance begins to ebb as a mechanism to increase the industry's efficiency of resource use, nutritionists need to more explicitly consider how diet formulation can enhance the efficiency of the enterprise by decreasing morbidity and mortality, limiting average days in milk (by decreasing postpartum time to pregnancy), and enhancing the resilience of animals undergoing environmental and physiological stress. A strength of our discipline has traditionally been our ability to see animals as an integrated system, and this has never been more important than in the age of Nutrition 2.0. The complexity of short- and long-term interacting nutrient effects is daunting. However, due to developments in molecular biology, dairy farm structure, and statistics, we can tackle these questions with a trio of valuable methods: proof-of-concept mechanistic studies, field studies, and meta-analysis. With increasingly detailed information available and the technology to apply nutritional strategies to pens and individuals, dairy farms will be able to adopt decision-tree nutrition programs that better support animals during traumatic times. With these types of strategies, there is great potential for the dairy industry to continue to make demonstrable progress in decreasing the resources needed to provide a growing population with dairy products. 


\section{ACKNOWLEDGMENTS}

This article is contribution no. 16-079-J from the Kansas Agricultural Experiment Station (Manhattan, $\mathrm{KS})$.

\section{REFERENCES}

Armsby, H. P. 1880. Manual of Cattle-Feeding: A treatise on the laws of animal nutrition and the chemistry of feeding-stuffs in their applications to the feeding of farm-animals. With illustrations and an appendix of useful tables. J. Wiley \& Sons, New York, NY.

Arriola Apelo, S. I., L. M. Singer, W. K. Ray, R. F. Helm, X. Y. Lin, M. L. McGilliard, N. R. St-Pierre, and M. D. Hanigan. 2014. Casein synthesis is independently and additively related to individual essential amino acid supply. J. Dairy Sci. 97:2998-3005.

Bach, A. 2014. Precision feeding to increase efficiency for milk production. Pages 177-189 in Proc. Western Canadian Dairy Seminar. Vol. 26. University of Alberta, Red Deer, Canada.

Bäckhed, F., R. E. Ley, J. L. Sonnenburg, D. A. Peterson, and J. I. Gordon. 2005. Host-bacterial mutualism in the human intestine. Science 307:1915-1920.

Bar, D., L. W. Tauer, G. Bennett, R. N. Gonzalez, J. A. Hertl, Y. H Schukken, H. F. Schulte, F. L. Welcome, and Y. T. Grohn. 2008. The cost of generic clinical mastitis in dairy cows as estimated by using dynamic programming. J. Dairy Sci. 91:2205-2214.

Baumgard, L. H., S. K. Stoakes, M. Abuajamieh, and R. P. Rhoads. 2015. The contribution of the lower gut to altered nutrient partitioning during stress. J. Dairy Sci. 98(Suppl. 2):560-561. (Abstr.)

Bourne, N., R. Laven, D. C. Wathes, T. Martinez, and M. McGowan. 2007. A meta-analysis of the effects of vitamin E supplementation on the incidence of retained foetal membranes in dairy cows. Theriogenology 67:494-501.

Bradford, B. J., K. J. Harvatine, and M. S. Allen. 2008. Dietary unsaturated fatty acids increase plasma glucagon-like peptide-1 and cholecystokinin and may decrease premeal ghrelin in lactating dairy cows. J. Dairy Sci. 91:1443-1450.

Buchanan, F. C., A. G. Van Kessel, C. Waldner, D. A. Christensen, B. Laarveld, and S. M. Schmutz. 2003. Hot topic: An association between a leptin single nucleotide polymorphism and milk and protein yield. J. Dairy Sci. 86:3164-3166.

Campbell, N. A. 1996. Biology. 4th ed. The Benjamin/Cummings Publishing Company Inc., Menlo Park, CA.

Carpenter, K. J. 2003. A short history of nutritional science: Part 3 (1912-1944). J. Nutr. 133:3023-3032.

Chaiyotwittayakun, A., R. J. Erskine, P. C. Bartlett, T. H. Herdt P. M. Sears, and R. J. Harmon. 2002. The effect of ascorbic acid and L-histidine therapy on acute mammary inflammation in dairy cattle. J. Dairy Sci. 85:60-67.

Chang, G., W. Petzl, J. Vanselow, J. Gunther, X. Shen, and H. M. Seyfert. 2015. Epigenetic mechanisms contribute to enhanced expression of immune response genes in the liver of cows after experimentally induced Escherichia coli mastitis. Vet. J. 203:339-341.

Chauhan, S. S., P. Celi, B. J. Leury, I. J. Clarke, and F. R. Dunshea. 2014. Dietary antioxidants at supranutritional doses improve oxidative status and reduce the negative effects of heat stress in sheep. J. Anim. Sci. 92:3364-3374.

Contreras-Govea, F. E., V. E. Cabrera, L. E. Armentano, R. D. Shaver, P. M. Crump, D. K. Beede, and M. J. VandeHaar. 2015. Constraints for nutritional grouping in Wisconsin and Michigan dairy farms. J. Dairy Sci. 98:1336-1344.

DePeters, E. J., and L. W. George. 2014. Rumen transfaunation. Immunol. Lett. 162:69-76.

Doelman, J., R. V. Curtis, M. Carson, J. J. Kim, J. A. Metcalf, and J. P. Cant. 2015. Essential amino acid infusions stimulate mammary expression of eukaryotic initiation factor $2 \mathrm{~B} \varepsilon$ but milk protein yield is not increased during an imbalance. J. Dairy Sci. 98:4499-4508.

Dong, G., M. Qiu, C. Ao, J. Zhou, E. Khas, X. Wang, Z. Zhang, and Y. Yang. 2014. Feeding a high-concentrate corn straw diet induced epigenetic alterations in the mammary tissue of dairy cows. PLoS ONE 9:e107659.

Dorrestein, P. C., S. K. Mazmanian, and R. Knight. 2014. Finding the missing links among metabolites, microbes, and the host. Immunity 40:824-832.

Dos Santos, C. O., E. Dolzhenko, E. Hodges, A. D. Smith, and G. J. Hannon. 2015. An epigenetic memory of pregnancy in the mouse mammary gland. Cell Reports 11:1102-1109.

Duffield, T. F., A. R. Rabiee, and I. J. Lean. 2008. A meta-analysis of the impact of monensin in lactating dairy cattle. Part 1. Metabolic effects. J. Dairy Sci. 91:1334-1346.

Dunshea, F. R., B. J. Leury, F. Fahri, K. DiGiacomo, A. Hung, S Chauhan, I. J. Clarke, R. Collier, S. Little, L. Baumgard, and J. B. Gaughan. 2013. Amelioration of thermal stress impacts in dairy cows. Anim. Prod. Sci. 53:965-975.

Efeyan, A., W. C. Comb, and D. M. Sabatini. 2015. Nutrient-sensing mechanisms and pathways. Nature 517:302-310.

Feeney, A., E. Nilsson, and M. Skinner. 2014. Epigenetics and transgenerational inheritance in domesticated farm animals. J. Anim. Sci. Biotechnol. 5:48.

Firkins, J. L., and Z. Yu. 2015. Ruminant Nutrition Symposium: How to use data on the rumen microbiome to improve our understanding of ruminant nutrition. J. Anim. Sci. 93:1450-1470.

Friggens, N. C., L. Brun-Lafleur, P. Faverdin, D. Sauvant, and O. Martin. 2013. Advances in predicting nutrient partitioning in the dairy cow: Recognizing the central role of genotype and its expression through time. Animal 7(Suppl. 1):89-101.

Gamas, L., P. Matafome, and R. Seica. 2015. Irisin and myonectin regulation in the insulin resistant muscle: Implications to adipose tissue: Muscle crosstalk. J. Diabetes Res. 2015:359159.

Gibney, M. J., and M. C. Walsh. 2013. The future direction of personalised nutrition: My diet, my phenotype, my genes. Proc. Nutr. Soc. 72:219-225.

Giesy, S. L., B. Yoon, W. B. Currie, J. W. Kim, and Y. R. Boisclair 2012. Adiponectin deficit during the precarious glucose economy of early lactation in dairy cows. Endocrinology 153:5834-5844.

Goff, J. P. 2006. Major advances in our understanding of nutritional influences on bovine health. J. Dairy Sci. 89:1292-1301.

González-Recio, O., E. Ugarte, and A. Bach. 2012. Trans-generational effect of maternal lactation during pregnancy: A Holstein cow model. PLoS ONE 7:e51816.

Grinberg, N., S. Elazar, I. Rosenshine, and N. Y. Shpigel. 2008. $\beta$-Hydroxybutyrate abrogates formation of bovine neutrophil extracellular traps and bactericidal activity against mammary pathogenic Escherichia coli. Infect. Immun. 76:2802-2807.

Hammon, H. M., J. Steinhoff-Wagner, J. Flor, U. Schonhusen, and C. C. Metges. 2013. Lactation Biology Symposium: role of colostrum and colostrum components on glucose metabolism in neonatal calves. J. Anim. Sci. 91:685-695.

Hammond, A. C. 1995. Leucaena toxicosis and its control in ruminants. J. Anim. Sci. 73:1487-1492.

Hartwell, J. R., M. J. Cecava, and S. S. Donkin. 2000. Impact of dietary rumen undegradable protein and rumen-protected choline on intake, peripartum liver triacylglyceride, plasma metabolites and milk production in transition dairy cows. J. Dairy Sci. 83:29072917.

Harvatine, K. J., Y. R. Boisclair, and D. E. Bauman. 2009. Recent advances in the regulation of milk fat synthesis. Animal 3:40-54.

Hotamisligil, G. S. 2006. Inflammation and metabolic disorders. Nature 444:860-867.

Ingvartsen, K. L., and K. Moyes. 2013. Nutrition, immune function and health of dairy cattle. Animal 7:112-122.

Jami, E., A. Israel, A. Kotser, and I. Mizrahi. 2013. Exploring the bovine rumen bacterial community from birth to adulthood. ISME J. 7:1069-1079.

Jami, E., and I. Mizrahi. 2012. Composition and similarity of bovine rumen microbiota across individual animals. PLoS ONE 7:e33306.

Kamiya, Y., M. Kamiya, and M. Tanaka. 2010. The effect of high ambient temperature on $\mathrm{Ca}, \mathrm{P}$ and $\mathrm{Mg}$ balance and bone turnover in high-yielding dairy cows. Anim. Sci. J. 81:482-486. 
Kenéz, A., L. Locher, J. Rehage, S. Danicke, and K. Huber. 2014. Agonists of the G protein-coupled receptor 109A-mediated pathway promote antilipolysis by reducing serine residue 563 phosphorylation of hormone-sensitive lipase in bovine adipose tissue explants. J. Dairy Sci. 97:3626-3634.

Kennedy, G. C. 1953. The role of depot fat in the hypothalamic control of food intake in the rat. Proc. R. Soc. Lond. B Biol. Sci. 140:578-596.

Khan, M. J., C. B. Jacometo, D. E. Graugnard, M. N. Correa, E. Schmitt, F. Cardoso, and J. J. Loor. 2014. Overfeeding dairy cattle during late-pregnancy alters hepatic PPARalpha-regulated pathways including hepatokines: Impact on metabolism and peripheral insulin sensitivity. Gene Regul. Syst. Bio. 8:97-111.

Kim, M. H., J. K. Seo, C. H. Yun, S. J. Kang, J. Y. Ko, and J. K. Ha. 2011. Effects of hydrolyzed yeast supplementation in calf starter on immune responses to vaccine challenge in neonatal calves. Animal 5:953-960.

Koeth, R. A., Z. Wang, B. S. Levison, J. A. Buffa, E. Org, B. T. Sheehy, E. B. Britt, X. Fu, Y. Wu, L. Li, J. D. Smith, J. A. DiDonato, J. Chen, H. Li, G. D. Wu, J. D. Lewis, M. Warrier, J. M. Brown, R. M. Krauss, W. H. W. Tang, F. D. Bushman, A. J. Lusis, and S. L. Hazen. 2013. Intestinal microbiota metabolism of L-carnitine, a nutrient in red meat, promotes atherosclerosis. Nat. Med. 19:576-585.

Komatsu, T., F. Itoh, S. Mikawa, and K. Hodate. 2003. Gene expression of resistin in adipose tissue and mammary gland of lactating and non-lactating cows. J. Endocrinol. 178:R1-R5.

Kononoff, P. J., P. J. Defoor, M. J. Engler, R. S. Swingle, S. T. James, H. M. Deobald, J. L. Deobald, and F. L. Marquess. 2013. Impact of a leptin single nucleotide polymorphism and zilpaterol hydrochloride on growth and carcass characteristics in finishing steers. J. Anim. Sci. 91:5011-5017.

Kosteli, A., E. Sugaru, G. Haemmerle, J. F. Martin, J. Lei, R. Zechner, and A. W. Ferrante. 2010. Weight loss and lipolysis promote a dynamic immune response in murine adipose tissue. J. Clin. Invest. 120:3466-3479.

Kushibiki, S., K. Hodate, H. Shingu, Y. Obara, E. Touno, M. Shinoda, and Y. Yokomizo. 2003. Metabolic and lactational responses during recombinant bovine tumor necrosis factor- $\alpha$ treatment in lactating cows. J. Dairy Sci. 86:819-827.

Lambrot, R., C. Xu, S. Saint-Phar, G. Chountalos, T. Cohen, M. Paquet, M. Suderman, M. Hallett, and S. Kimmins. 2013. Low paternal dietary folate alters the mouse sperm epigenome and is associated with negative pregnancy outcomes. Nat. Commun. 4:2889.

Lean, I. J., M. C. Lucy, J. P. McNamara, B. J. Bradford, E. Block, J. M. Thomson, J. M. Morton, P. Celi, A. R. Rabiee, J. E.-P. Santos, W. W. Thatcher, and S. J. LeBlanc. 2016. Recommendations for reporting intervention studies on reproductive performance in dairy cattle: Improving design, analysis and interpretation of research on reproduction. J. Dairy Sci. 99:1-17. http://dx.doi. org/10.3168/jds.2015-9445.

LeBlanc, S. J., K. D. Lissemore, D. F. Kelton, T. F. Duffield, and K. E. Leslie. 2006. Major advances in disease prevention in dairy cattle. J. Dairy Sci. 89:1267-1279.

Liang, G., N. Malmuthuge, L. L. Guan, and P. Griebel. 2015. Model systems to analyze the role of miRNAs and commensal microflora in bovine mucosal immune system development. Mol. Immunol. 66:57-67.

Lima, F. S., M. F. Sá Filho, L. F. Greco, and J. E. P. Santos. 2012. Effects of feeding rumen-protected choline on incidence of diseases and reproduction of dairy cows. Vet. J. 193:140-145.

Lochmiller, R. L., and C. Deerenberg. 2000. Trade-offs in evolutionary immunology: Just what is the cost of immunity? Oikos 88:87-98.

Longuski, R. A., Y. Ying, and M. S. Allen. 2009. Yeast culture supplementation prevented milk fat depression by a short-term dietary challenge with fermentable starch. J. Dairy Sci. 92:160-167.

Lu, J., H. Meng, A. Zhang, J. Yang, and X. Zhang. 2015. Phenotype and function of tissue-resident unconventional Foxp3-expressing CD4 regulatory T cells. 297:53-59. Cell. Immunol. http://dx.doi. org/10.1016/j.cellimm.2015.1006.1005.
Machado, V. S., M. L. Bicalho, R. V. Pereira, L. S. Caixeta, W. A. Knauer, G. Oikonomou, R. O. Gilbert, and R. C. Bicalho. 2013. Effect of an injectable trace mineral supplement containing selenium, copper, zinc, and manganese on the health and production of lactating Holstein cows. Vet. J. 197:451-456.

Macpherson, A. J., and N. L. Harris. 2004. Interactions between commensal intestinal bacteria and the immune system. Nat. Rev. Immunol. 4:478-485.

Manosalva, C., J. Mena, Z. Velasquez, C. K. Colenso, S. Brauchi, R. A. Burgos, and M. A. Hidalgo. 2015. Cloning, identification and functional characterization of bovine free fatty acid receptor-1 (FFAR1/GPR40) in neutrophils. PLoS ONE 10:e119715.

Marshall, A. M., L. L. Hernandez, and N. D. Horseman. 2014. Serotonin and serotonin transport in the regulation of lactation. J. Mammary Gland Biol. Neoplasia 19:139-146.

McArt, J. A., D. V. Nydam, and M. W. Overton. 2015. Hyperketonemia in early lactation dairy cattle: A deterministic estimate of component and total cost per case. J. Dairy Sci. 98:2043-2054.

Meale, S. J., J. M. Romao, M. L. He, A. V. Chaves, T. A. McAllister, and L. L. Guan. 2014. Effect of diet on microRNA expression in ovine subcutaneous and visceral adipose tissues. J. Anim. Sci. 92:3328-3337.

Meijer, R., and K. Peeters. 2010. The use of precision dairy farming in feeding and nutrition. Proc. The First North American Conference on Precision Dairy Management 2010, Toronto, Canada. Accessed Aug. 5, 2015. http://precisiondairy.com/conferenceproceedings. htm.

Michal, J. J., L. R. Heirman, T. S. Wong, B. P. Chew, M. Frigg, and L. Volker. 1994. Modulatory effects of dietary $\beta$-carotene on blood and mammary leukocyte function in periparturient dairy cows. J. Dairy Sci. 77:1408-1421.

Morey, S. D., L. K. Mamedova, D. E. Anderson, C. K. Armendariz, E. C. Titgemeyer, and B. J. Bradford. 2011. Effects of encapsulated niacin on metabolism and production of periparturient dairy cows. J. Dairy Sci. 94:5090-5104.

Nelson, C. D., T. A. Reinhardt, J. D. Lippolis, R. E. Sacco, and B. J. Nonnecke. 2012. Vitamin D signaling in the bovine immune system: A model for understanding human vitamin D requirements. Nutrients 4:181-196.

Nguyen, K. D., Y. Qiu, X. Cui, Y. P. Goh, J. Mwangi, T. David, L. Mukundan, F. Brombacher, R. M. Locksley, and A. Chawla. 2011. Alternatively activated macrophages produce catecholamines to sustain adaptive thermogenesis. Nature 480:104-108.

NRC. 2001. Nutrient Requirements of Dairy Cattle. 7th rev. ed. Natl. Acad. Sci., Washington, DC.

O'Doherty, A. M., A. O'Gorman, A. al Naib, L. Brennan, E. Daly, P. Duffy, and T. Fair. 2014. Negative energy balance affects imprint stability in oocytes recovered from postpartum dairy cows. Genomics 104:177-185.

Odegaard, J. I., and A. Chawla. 2013. The immune system as a sensor of the metabolic state. Immunity 38:644-654.

Odongo, N. E., O. Alzahal, M. I. Lindinger, T. F. Duffield, E. V. Valdes, S. P. Terrell, and B. W. McBride. 2006. Effects of mild heat stress and grain challenge on acid-base balance and rumen tissue histology in lambs. J. Anim. Sci. 84:447-455.

Oldknow, K. J., V. E. MacRae, and C. Farquharson. 2015. Endocrine role of bone: Recent and emerging perspectives beyond osteocalcin. J. Endocrinol. 225:R1-R19.

Peñagaricano, F., A. H. Souza, P. D. Carvalho, A. M. Driver, R. Gambra, J. Kropp, K. S. Hackbart, D. Luchini, R. D. Shaver, M. C. Wiltbank, and H. Khatib. 2013. Effect of maternal methionine supplementation on the transcriptome of bovine preimplantation embryos. PLoS ONE 8:e72302.

Piantoni, P., A. L. Lock, and M. S. Allen. 2015. Saturated fat supplementation interacts with dietary forage neutral detergent fiber content during the immediate postpartum and carryover periods in Holstein cows: Production responses and digestibility of nutrients. J. Dairy Sci. 98:3309-3322.

Pickard, J. M., C. F. Maurice, M. A. Kinnebrew, M. C. Abt, D. Schenten, T. V. Golovkina, S. R. Bogatyrev, R. F. Ismagilov, E. G. Pamer, P. J. Turnbaugh, and A. V. Chervonsky. 2014. Rapid 
fucosylation of intestinal epithelium sustains host-commensal symbiosis in sickness. Nature 514:638-641.

Plaut, K., and T. Casey. 2012. Does the circadian system regulate lactation? Animal 6:394-402.

Reis, M. M., R. F. Cooke, J. Ranches, and J. L. Vasconcelos. 2012. Effects of calcium salts of polyunsaturated fatty acids on productive and reproductive parameters of lactating Holstein cows. J. Dairy Sci. 95:7039-7050.

Relling, A. E., and C. K. Reynolds. 2007. Plasma concentrations of gut peptides in dairy cattle increase after calving. J. Dairy Sci. 90:325-330.

Rincon, G., A. Islas-Trejo, A. R. Castillo, D. E. Bauman, B. J. German, and J. F. Medrano. 2012. Polymorphisms in genes in the SREBP1 signalling pathway and SCD are associated with milk fatty acid composition in Holstein cattle. J. Dairy Res. 79:66-75.

Rius, A. G., J. A. D. R. N. Appuhamy, J. Cyriac, D. Kirovski, O Becvar, J. Escobar, M. L. McGilliard, B. J. Bequette, R. M. Akers, and M. D. Hanigan. 2010. Regulation of protein synthesis in mammary glands of lactating dairy cows by starch and amino acids. J. Dairy Sci. 93:3114-3127.

Rodney, R. M., P. Celi, W. Scott, K. Breinhild, and I. J. Lean. 2015. Effects of dietary fat on fertility of dairy cattle: A meta-analysis and meta-regression. J. Dairy Sci. 98:5601-5620.

Rottman, L. W., Y. Ying, K. Zhou, P. A. Bartell, and K. J. Harvatine. 2014. The daily rhythm of milk synthesis is dependent on the timing of feed intake in dairy cows. Physiol. Rep. 2:e12049.

Sanchez, W. K., M. A. McGuire, and D. K. Beede. 1994. Macrominera nutrition by heat stress interactions in dairy cattle: Review and original research. J. Dairy Sci. 77:2051-2079.

Sato, R., K. Onda, H. Ochiai, T. Iriki, Y. Yamazaki, and Y. Wada. 2011. Serum osteocalcin in dairy cows: Age-related changes and periparturient variation. Res. Vet. Sci. 91:196-198.

Sauerwein, H., E. Bendixen, L. Restelli, and F. Ceciliani. 2014. The adipose tissue in farm animals: A proteomic approach. Curr. Protein Pept. Sci. 15:146-155.

Schoenberg, K. M., S. L. Giesy, K. J. Harvatine, M. R. Waldron, C. Cheng, A. Kharitonenkov, and Y. R. Boisclair. 2011. Plasma FGF21 is elevated by the intense lipid mobilization of lactation. Endocrinology 152:4652-4661

Sharon, G., N. Garg, J. Debelius, R. Knight, P. C. Dorrestein, and S. K. Mazmanian. 2014. Specialized metabolites from the microbiome in health and disease. Cell Metab. 20:719-730.

Singh, S. P., S. Haussler, J. F. Heinz, S. H. Akter, B. Saremi, U. Muller, J. Rehage, S. Danicke, M. Mielenz, and H. Sauerwein. 2014. Lactation driven dynamics of adiponectin supply from different fat depots to circulation in cows. Domest. Anim. Endocrinol. 47:35-46.

Smith, K. L., J. H. Harrison, D. D. Hancock, D. A. Todhunter, and H. R. Conrad. 1984. Effect of vitamin E and selenium supplementation on incidence of clinical mastitis and duration of clinical symptoms. J. Dairy Sci. 67:1293-1300.

Sordillo, L. M., and V. Mavangira. 2014. The nexus between nutrient metabolism, oxidative stress and inflammation in transition cows. Anim. Prod. Sci. 54:1204-1214.

St-Pierre, N., B. Cobanov, and G. Schnitkey. 2003. Economic losses from heat stress by US livestock industries. J. Dairy Sci. 86:E52E77.

St-Pierre, N. R., and W. P. Weiss. 2012. Nutrient requirements, responses and feed efficiency. Pages 1-7 in Proc. Four-State Dairy Nutrition and Management Conference. Iowa State University, Ames.

Stanya, K. J., D. Jacobi, S. Liu, P. Bhargava, L. Dai, M. R. Gangl, K. Inouye, J. L. Barlow, Y. Ji, J. P. Mizgerd, L. Qi, H. Shi, A. N. J. McKenzie, and C.-H. Lee. 2013. Direct control of hepatic glucose production by interleukin-13 in mice. J. Clin. Invest. 123:261-271.

Steele, M. A., G. B. Penner, F. Chaucheyras-Durand, and L. L. Guan. 2016. Development and physiology of the rumen and the lower gut: Targets for improving gut health. J. Dairy Sci. 99:4955-4966. http://dx.doi.org/10.3168/jds.2015-10351.

Steele, M. A., J. Croom, M. Kahler, O. AlZahal, S. E. Hook, K. Plaizier, and B. W. McBride. 2011. Bovine rumen epithelium undergoes rapid structural adaptations during grain-induced subacute ruminal acidosis. Am. J. Physiol. Regul. Integr. Comp. Physiol. 300:R1515-R1523.

Sugino, T., Y. Hasegawa, Y. Kikkawa, J. Yamaura, M. Yamagishi, Y. Kurose, M. Kojima, K. Kangawa, and Y. Terashima. 2002. A transient ghrelin surge occurs just before feeding in a scheduled meal-fed sheep. Biochem. Biophys. Res. Commun. 295:255-260.

Trevisi, E., M. Amadori, F. Riva, G. Bertoni, and P. Bani. 2014 Evaluation of innate immune responses in bovine forestomachs. Res. Vet. Sci. 96:69-78.

USDA. 2014. Census of Agriculture 2012. Accessed Aug. 8, 2015. http://www.agcensus.usda.gov/Publications/2012/.

VandeHaar, M. J., L. E. Armentano, K. Weigel, D. M. Spurlock, R. J. Templeman, and R. Veerkamp. 2016. Harnessing the genetics of the modern dairy cow to continue improvements in feed efficiency. J. Dairy Sci. 99:4941-4954. http://dx.doi.org/10.3168/ jds.2015-10352.

Vanselow, J., W. Yang, J. Herrmann, H. Zerbe, H.-J. Schuberth, W. Petzl, W. Tomek, and H.-M. Seyfert. 2006. DNA-remethylation around a STAT5-binding enhancer in the $\alpha$ S1-casein promoter is associated with abrupt shutdown of $\alpha$ S1-casein synthesis during acute mastitis. J. Mol. Endocrinol. 37:463-477.

Wallace, R. J., and C. J. Newbold. 1992. Probiotics for ruminants Pages 317-353 in Probiotics. Springer, Amsterdam, the Netherlands.

Wang, A., Z. Gu, B. Heid, R. M. Akers, and H. Jiang. 2009. Identification and characterization of the bovine $\mathrm{G}$ protein-coupled receptor GPR41 and GPR43 genes. J. Dairy Sci. 92:2696-2705.

Weimer, P. J., D. M. Stevenson, H. C. Mantovani, and S. L. Man 2010. Host specificity of the ruminal bacterial community in the dairy cow following near-total exchange of ruminal contents. J. Dairy Sci. 93:5902-5912.

Wu, S., R. W. Li, W. Li, and C.-j. Li. 2012. Transcriptome characterization by RNA-seq unravels the mechanisms of butyrate-induced epigenomic regulation in bovine cells. PLoS ONE 7:e36940.

Youm, Y. H., K. Y. Nguyen, R. W. Grant, E. L. Goldberg, M. Bodogai, D. Kim, D. D'Agostino, N. Planavsky, C. Lupfer, T. D. Kanneganti, S. Kang, T. L. Horvath, T. M. Fahmy, P. A. Crawford, A. Biragyn, E. Alnemri, and V. D. Dixit. 2015. The ketone metabolite beta-hydroxybutyrate blocks NLRP3 inflammasome-mediated inflammatory disease. Nat. Med. 21:263-269.

Yuan, K., L. G. Mendonca, L. E. Hulbert, L. K. Mamedova, M. B. Muckey, Y. Shen, C. C. Elrod, and B. J. Bradford. 2015. Yeast product supplementation modulated humoral and mucosal immunity and uterine inflammatory signals in transition dairy cows. J. Dairy Sci. 98:3236-3246.

Yutang, L. 1937. The Importance of Living. Reynal \& Hitchcock Inc., New York, NY.

Zahra, L. C., T. F. Duffield, K. E. Leslie, T. R. Overton, D. Putnam, and S. J. LeBlanc. 2006. Effects of rumen-protected choline and monensin on milk production and metabolism of periparturient dairy cows. J. Dairy Sci. 89:4808-4818.

Zaworski, E. M., C. M. Shriver-Munsch, N. A. Fadden, W. K. Sanchez, I. Yoon, and G. Bobe. 2014. Effects of feeding various dosages of Saccharomyces cerevisiae fermentation product in transition dairy cows. J. Dairy Sci. 97:3081-3098.

Zhang, S., R. I. Albornoz, J. R. Aschenbach, D. R. Barreda, and G. B. Penner. 2013. Short-term feed restriction impairs the absorptive function of the reticulo-rumen and total tract barrier function in beef cattle. J. Anim. Sci. 91:1685-1695. 